\title{
Damage Detection and Localization from Dense Network of Strain Sensors
}

\author{
Simon Laflamme, ${ }^{1,2}$ Liang Cao, ${ }^{1}$ Eleni Chatzi, ${ }^{3}$ and Filippo Ubertini ${ }^{4}$ \\ ${ }^{1}$ Department of Civil, Construction, and Environmental Engineering, Iowa State University, Ames, IA 50011, USA \\ ${ }^{2}$ Department of Electrical and Computer Engineering, Iowa State University, Ames, IA 50011, USA \\ ${ }^{3}$ Institute of Structural Engineering, Department of Civil, Environmental \& Geomatic Engineering, \\ ETH Zürich, 8093 Zürich, Switzerland \\ ${ }^{4}$ Department of Civil and Environmental Engineering, University of Perugia, 06125 Perugia, Italy
}

Correspondence should be addressed to Filippo Ubertini; filippo.ubertini@unipg.it

Received 2 July 2015; Accepted 27 September 2015

Academic Editor: Sakdirat Kaewunruen

Copyright (C) 2016 Simon Laflamme et al. This is an open access article distributed under the Creative Commons Attribution License, which permits unrestricted use, distribution, and reproduction in any medium, provided the original work is properly cited.

\begin{abstract}
Structural health monitoring of large systems is a complex engineering task due to important practical issues. When dealing with large structures, damage diagnosis, localization, and prognosis necessitate a large number of sensors, which is a nontrivial task due to the lack of scalability of traditional sensing technologies. In order to address this challenge, the authors have recently proposed a novel sensing solution consisting of a low-cost soft elastomeric capacitor that transduces surface strains into measurable changes in capacitance. This paper demonstrates the potential of this technology for damage detection, localization, and prognosis when utilized in dense network configurations over large surfaces. A wind turbine blade is adopted as a case study, and numerical simulations demonstrate the effectiveness of a data-driven algorithm relying on distributed strain data in evidencing the presence and location of damage, and sequentially ranking its severity. Numerical results further show that the soft elastomeric capacitor may outperform traditional strain sensors in damage identification as it provides additive strain measurements without any preferential direction. Finally, simulation with reconstruction of measurements from missing or malfunctioning sensors using the concepts of virtual sensors and Kriging demonstrates the robustness of the proposed condition assessment methodology for sparser or malfunctioning grids.
\end{abstract}

\section{Introduction}

Damage diagnosis, localization, and prognosis on large structural surfaces, or mesosurfaces, are a complex task due to the large geometries under monitoring. Traditional off-the-shelf sensing solutions can difficultly be deployed in their unaltered form, because of important scalability limitations. For example, accelerometers are often used for global vibrationbased monitoring of structures [1-3], but they necessitate complex signal processing algorithms to enable damage diagnosis and localization over large geometries. Also, resistive foil gauges are geometrically too small to be capable of diagnosing and localizing a damage within an acceptable level of probability [4].
A solution to the mesoscale challenge in structural health monitoring is to engineer and deploy large arrays of sensors. The literature counts successful application examples of sensor networks capable of damage diagnosis and localization after a strategic deployment. This includes piezoelectric wafer active sensors (PWAS) networks [5, 6], as well as fiber opticsbased technologies [7-9]. Some authors have also studied the deployment of electrically conductive nanoparticle networks, such as carbon nanotubes, within cement-based materials, to detect local damage in structures [10-12]. Recent advances in the field of flexible electronics have enabled the fabrication of large area electronics (LAE) that can be deployed at largescales. LAE technologies are often analogous to sensing skin, in the sense that they are capable of discrete sensing over 


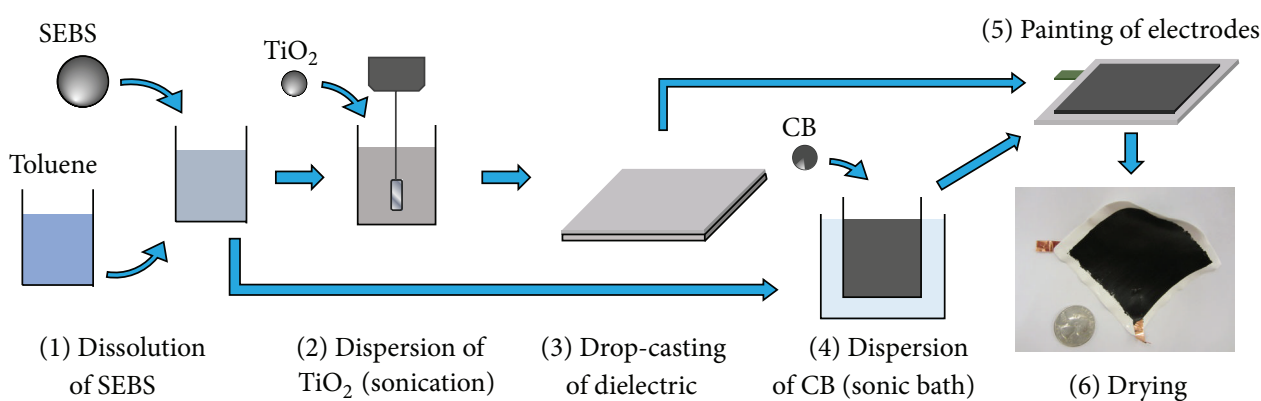

FIgURE 1: Fabrication process of the SEC.

large areas. Examples of LAE for structural health monitoring include flexible strain sensors [13-15] and sensing sheets [16, 17].

We have recently proposed a highly scalable LAE for strain measurement over large surfaces [18]. The sensor is a soft elastomeric capacitor (SEC). The sensing principle is based on a measurable change in capacitance that occurs upon a change in the sensor's geometry. The capacity of the SEC at detecting and localizing fatigue cracks in a network configuration using pure strain data has been experimentally demonstrated in [19]. Damage detection and localization were conducted by comparing the levels of strain readings, where a fatigue crack would provoke a significant change in a particular sensor reading. However, unlike traditional resistive strain gauges, the SEC measures additive in-plane strain components, where both the principal strain components and directions are hidden in the information. An algorithm has been proposed to decompose measurements from an SEC network into principal components to reconstruct strain maps, but it requires accurate assumptions on the system's boundary conditions in order to perform accurately [20].

In this paper, we propose to leverage dense network applications of the SEC to detect and localize damage and to evaluate its severity. This is an improvement to prior work, which does not rely on surges in sensor readings or on assumptions on boundary conditions. Instead, the algorithm consists of comparing the spatial and temporal sensor relative responses and evaluating changes in such responses. While the methodology is applicable to any network of strain gauges, it will be demonstrated that the additive strain measurement feature of the SEC is an advantage, as it enables a more accurate damage localization.

The paper is organized as follows. Section 2 gives the background on the SEC technology, including a description of the fabrication process and a derivation of its additive measurement features. Section 3 describes the research methodology. Section 4 presents and discusses results from numerical simulations on a wind turbine blade. Section 5 extends the simulations to the case of missing or malfunctioning sensors. Section 6 concludes the paper.

\section{Background}

This section provides the background on the SEC technology. It first describes its fabrication process and then derives its electromechanical model.
2.1. Sensor Fabrication. The fabrication process of the SEC is described in details in [22] and illustrated in Figure 1. Briefly, its dielectric is fabricated by dissolving a styrene-coethylene-co-butylene-co-styrene (SEBS) matrix into toluene (Figure 1(step (1))) and incorporating titanium dioxide $\left(\mathrm{TiO}_{2}\right)$ via sonication to increase the permittivity of the material (Figure 1(step (2))) before drop-casting the solution on a glass plate to allow evaporation of the toluene (Figure 1(step (3))). While the dielectric is drying, carbon black (CB) particles are added to a solution of SEBS and dispersed in a sonication bath to create a conductive paint (Figure 1(step (4))). Both surfaces of the dielectric are painted with the CB-SEBS solution to create the electrodes and copper tapes are embedded in the paint to create mechanical connections to the wires (Figure 1(step (5))) and allowed to dry (Figure 1(step (6))).

The geometry of the sensor is governed by the geometry of the glass plate used for the drop-cast process. It is customizable in shapes and sizes. The SEBS matrix, $\mathrm{TiO}_{2}$, and $\mathrm{CB}$ are all relatively inexpensive materials. Combined with the simple fabrication process listed above, the economical feature of the sensing technology highly facilitates its scalability. Figure 2(a) is a picture of a single SEC measuring $76.2 \times 76.2 \mathrm{~mm}^{2}(3 \times$ $\left.3 \mathrm{in}^{2}\right)$.

2.2. Electromechanical Model. The electromechanical model of the sensor can be derived as follows. Within the low frequency range $(<1 \mathrm{kHz})$ the $\mathrm{SEC}$ can be approximated as a nonlossy capacitor:

$$
C=\frac{e_{0} e_{r} A}{h_{d}},
$$

where $C$ is the capacitance, $A=w \cdot l$ the surface area of the electrodes of width $w$ and length $l, h_{d}$ the thickness of the dielectric (Figure 2(b)), $e_{0}=8.854 \mathrm{pF} / \mathrm{m}$ the vacuum permittivity, and $e_{r}$ the dimensionless relative permittivity $\left(e_{r} \approx\right.$ 4.2). A deformation of the sensor is measured as a change in capacitance $\Delta C$. For small changes in geometry, and considering the reference system depicted in Figure 2(b), where the $z$-axis is normal to the monitored surface, (1) can be differentiated to obtain an expression for $\Delta C$ as a function of the monitored strain:

$$
\frac{\Delta C}{C}=\left(\frac{\Delta l}{l}+\frac{\Delta w}{w}-\frac{\Delta h}{h}\right)=\varepsilon_{x}+\varepsilon_{y}-\varepsilon_{z}
$$




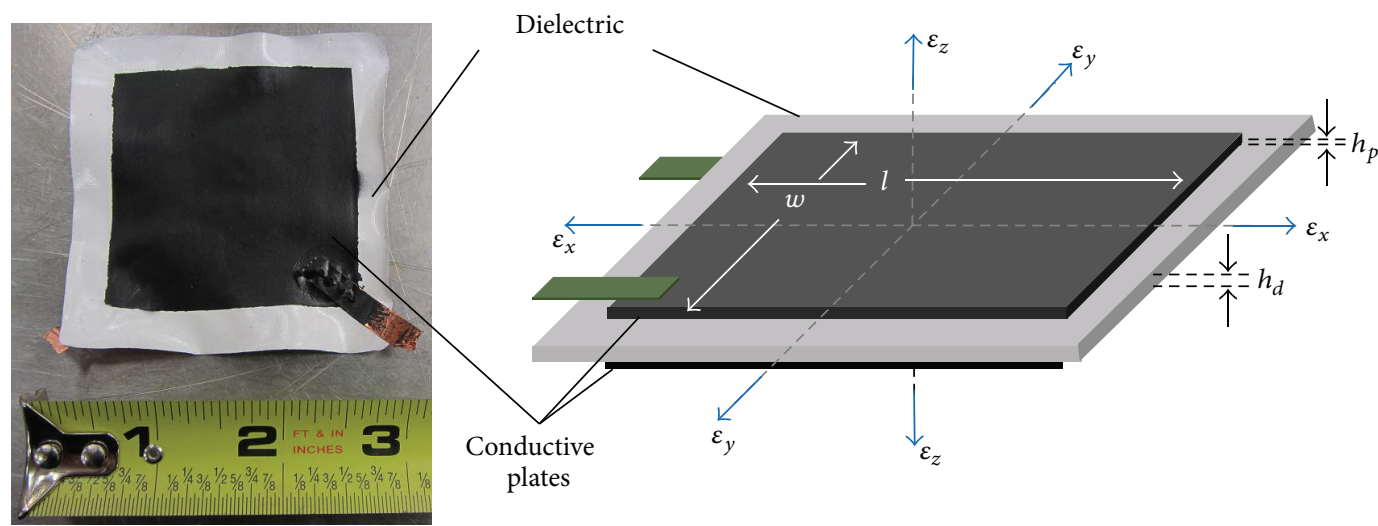

(a)

(b)

FIgURE 2: (a) A picture of a single SEC $\left(76.2 \times 76.2 \mathrm{~mm}^{2}\left(3 \times 3 \mathrm{in}^{2}\right)\right)$ and (b) schematic of SEC with principal axes.

and using Hooke's Law under plane stress assumption, the strain along the $z$-axis can be written:

$$
\varepsilon_{z}=-\frac{v}{1-v}\left(\varepsilon_{x}+\varepsilon_{y}\right)
$$

where $v$ is Poisson's coefficient of the sensor material. The gauge factor $\lambda$ of the SEC is readily obtained by substituting (3) into (2):

$$
\frac{\Delta C}{C}=\lambda\left(\varepsilon_{x}+\varepsilon_{y}\right)
$$

where

$$
\lambda=\frac{1}{1-v} .
$$

Equation (4) shows that the sensor's output $\Delta C$, which can be measured via a data acquisition system, is proportional to the sum of $\varepsilon_{x}$ and $\varepsilon_{y}$, which is referred to as the additive in-plane strain measurement feature.

2.3. Validation. The SEC and its electromechanical model have been validated in [18]. This subsection summarizes a key result from an experiment conducted over small strain $(0$ to $850 \mu \varepsilon)$. In the experiment, the SEC was adhered onto the bottom surface of a simply supported beam. The beam was subjected to a three-point quasi-static load using a servohydraulic testing machine (MTS). The load consisted of a triangular load of frequency varying from 0.0167 to $0.40 \mathrm{~Hz}$. An off-the-shelf resistive foil gauge of resolution $1 \mu \varepsilon$ (Vishay Micro-Measurements, CEA-06-500UW-120) was adhered next to the SEC to measure the applied bending strain. Data from the SEC were acquired using an off-the-shelf capacitance data acquisition system (ACAM PCap01) and sampled at $95.4 \mathrm{~Hz}$, and the foil gauge data were acquired using a Hewlett-Packard 3852 and sampled at $1.7 \mathrm{~Hz}$. Data from the SEC were converted into strain using (4) specialized for uniaxial strain. The test was repeated three times. Figure 3 is a plot of a typical result. The measured strain (from the SEC) agrees with the applied strain (measured from the resistive foil gauge). The precision of the SEC is approximately $25 \mu \varepsilon$.

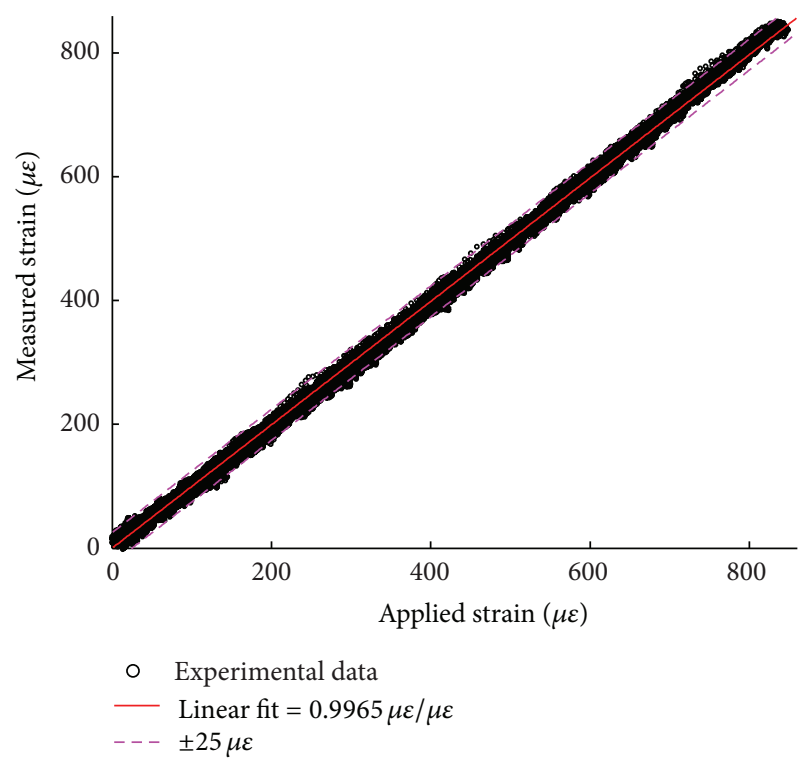

FIGURE 3: Measured (from SEC) versus applied (from foil gauge) strains.

\section{Methodology}

The capacity of a network of SECs at detecting, localizing, and estimating the severity of damage using the pure signal from (4) is investigated via numerical simulations. This section describes the algorithm used for damage detection and localization, along with the numerical model.

3.1. Algorithm. The algorithm for damage detection and localization consists of comparing spatial and temporal relative measurements of SECs within a sensor network comprising $S$ sensors. At any time, the response of a sensor is compared with the average response of its nearest neighbors:

$$
r_{i, t}=\frac{s_{i, t}}{\sum_{j \in S_{i}} s_{j, t} / n_{i}}
$$


TABLE 1: Material properties for the wind turbine blade model.

\begin{tabular}{lcccccc}
\hline Layer & Material (orientation) & $E_{x}(\mathrm{GPa})$ & $E_{y}(\mathrm{GPa})$ & $G_{x y}(\mathrm{GPa})$ & Density $\left(\mathrm{kg} / \mathrm{m}^{3}\right)$ & Thickness $(\mathrm{mm})$ \\
\hline 1 & Carbon-fiberglass fabric $\left(+45^{\circ}\right)$ & 84.10 & 8.76 & 4.38 & 3469 & 13 \\
2 & C520 fiberglass $\left(0^{\circ}\right)$ & 37.30 & 7.60 & 6.89 & 1874 & 9 \\
3 & Carbon-fiberglass fabric $\left(-45^{\circ}\right)$ & 84.10 & 8.76 & 4.38 & 3469 & 13 \\
\hline
\end{tabular}

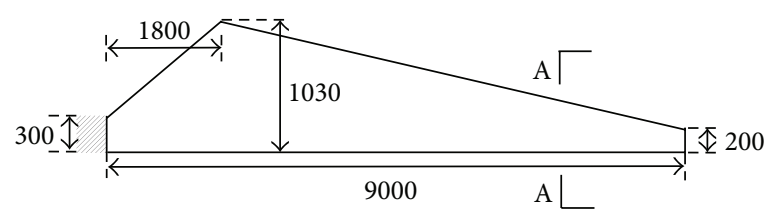

(a)

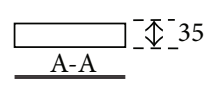

(b)

FIGURE 4: Wind turbine blade dimensions (mm) (a) top view and (b) cross section.

where $s_{i, t}$ is the measurement of the $i$ th sensor at time $t$ and the sum in the denominator is extended to the subset, $S_{i}$, composed by the $n_{i}$ sensors that are in the neighborhood of the $i$ th sensor. Neighboring sensors are determined and ranked in terms of Euclidean distance. Following this definition, $r_{i, t}$ is the relative response of sensor $i$ with respect to its $n_{i}$ closest neighbors. A map of relative responses can be constructed by assembling all $r_{i, t}$ at a particular time $t$ for $i=1, \ldots, S$, denoted by $R_{t}$. A damage index map, $J_{t}$, can be constructed by comparing $R_{t}$ with a reference map $R_{t^{*}}$ :

$$
J_{t}=R_{t^{*}}-R_{t}
$$

In a dynamic loading case, $R_{t^{*}}$ and $R_{t}$ can be the average values taken over a finite period of time, $T$ :

$$
\bar{R}_{t}=\frac{1}{T} \int_{0}^{T} R_{t} \mathrm{~d} t
$$

with

$$
\bar{J}_{t}=\bar{R}_{t^{*}}-\bar{R}_{t}
$$

A negative value of $J_{t}$ at a particular sensing location indicates that the sensor has a larger relative response with respect to its closest neighbors, thus suggesting a possible local plasticization of the monitored structure. Conversely, a positive value would indicate that its relative response decreased, thus having the possibility of a change in the load path. In the numerical simulations, different damage cases will be compared. Following the notation above, $\bar{R}_{t^{*}}$ will consist of the average relative response map for the undamaged case, while $\bar{R}_{t}$ will correspond to the average relative response map under various damage cases. Note that this comparison of relative responses enables a temporal comparison of sensor responses independent of the input, thus making this an output-only condition assessment technique.

3.2. Numerical Model. The numerical model used for the simulations represents a 9-meter wind turbine blade, modeled after the CX-100 carbon fiber wind turbine blade [23]. This particular blade has been used in numerous studies
TABLE 2: Comparison of model and experimental frequencies.

\begin{tabular}{lccc}
\hline Frequency & Model $(\mathrm{Hz})$ & Experimental $(\mathrm{Hz})[21]$ & Difference $(\%)$ \\
\hline Flatwise & 4.16 & 4.56 & -8.8 \\
Edgewise & 8.02 & 7.49 & +7.1 \\
\hline
\end{tabular}

(see [21, 24, 25], for instance). A finite element model of a simplified representation of the CX-100 blade was generated in ANSYS using shell elements. It consists of a tapered cantilever plate of $9 \mathrm{~m}$ length, $1.03 \mathrm{~m}$ largest width, and $0.035 \mathrm{~m}$ thickness, as shown in Figure 4. The plate is modeled with 3 different layers and orientations, and with 2 different materials as listed in Table 1.

The plate boundary (fixity) was modeled to approximately match the first flatwise and edgewise frequencies reported in [21]. Table 2 lists the model and experimental values, showing an agreement within a $10 \%$ difference, taken as acceptable given the simplified model.

3.2.1. Wind Loads. The blade was subjected to different wind load representations generated using the procedure described in [26]. Briefly, the wind speed, $v_{w}(t)$, is assumed to have a perfect spatial correlation over the blade, due to its relatively small dimensions, and is modeled as

$$
v_{w}(t)=v_{a}+v_{r}(t)+v_{g}(t)+v_{t}(t)
$$

where $v_{a}$ is the average wind speed, $v_{r}$ the wind speed ramp, $v_{g}$ the wind gust, and $v_{t}$ the wind turbulence. The wind speed ramp is taken as

$$
\nu_{r}= \begin{cases}0 & \text { if } t<T_{s r} \\ v_{\text {ramp }} & \text { if } T_{s r}<t<T_{e r} \\ 0 & \text { if } t>T_{e r}\end{cases}
$$

where $v_{\text {ramp }}=A_{\text {ramp }}\left(\left(t-T_{s r}\right) /\left(T_{e r}-T_{s r}\right)\right), A_{\text {ramp }}$ is the amplitude of wind speed ramp, and $T_{s r}$ and $T_{e r}$ are the starting 
and end times of wind speed ramp, respectively. The wind speed gust is characterized by

$$
v_{g}(t)= \begin{cases}0 & \text { if } t<T_{s g}, \\ v_{\text {gust }}(t) & \text { if } T_{s g}<t<T_{e g} \\ 0 & \text { if } t>T_{e g}\end{cases}
$$

where $v_{\text {gust }}(t)=A_{\text {gust }}\left(1-\cos \left(2 \pi\left(\left(t-T_{s g}\right) /\left(T_{e g}-T_{s g}\right)\right)\right)\right)$ with $A_{\text {gust }}$ being the amplitude of the wind speed gust and $T_{s g}$ and $T_{e g}$ are the starting and end times of wind speed gust, respectively. Under the classic assumption of modeling wind turbulence as a zero-mean Gaussian stochastic process, its time domain realization is generated by the waves superposition formula as follows $[27,28]$ :

$$
v_{t}(t)=\sqrt{2} \sum_{k=1}^{N}\left[P_{D}\left(\omega_{k}\right) \Delta \omega\right]^{1 / 2} \cos \left(\omega_{k} t+\phi_{k}\right),
$$

where $\omega_{k}$ is the frequency $(\mathrm{Hz}), \phi_{k}$ is a random phase uniformly distributed between 0 and $2 \pi$, and $P_{D}\left(\omega_{k}\right)$ is the power spectral density function of wind turbulence [26]:

$$
P_{D}\left(\omega_{k}\right)=\operatorname{l\nu } a\left(\ln \left(\frac{h}{z_{0}}\right)^{2}\right)^{-1}\left(1+1.5 \frac{\omega_{k} l}{\nu_{a}}\right)^{-5 / 3},
$$

where $h$ is the height from the ground (m), $l$ is the turbulence length scale $(\mathrm{m})$, and $z_{0}$ is the roughness length $(\mathrm{m})$ that can be determined from [29]. In (14) the wind spectrum is discretized using $N_{\omega}$ equally spaced frequency points, $\omega_{k}=k \Delta \omega$, with a frequency step amplitude $\Delta \omega$ and a cutoff frequency $\omega_{c}=N_{\omega} \Delta \omega$. Finally, the wind pressure $P_{w}(t)$ acting over the blade is obtained using [30]

$$
P_{w}(t)=0.5 \rho v_{w}(t)^{2} C_{p},
$$

where $\rho$ is the air density and $C_{p}$ is a constant denoting the combined pressure coefficient.

Wind pressure generated by (15) is applied as a uniform pressure onto the top surface of the wind turbine blade model. Each damage case (described below) is simulated under a different wind load realization using the same base parameters listed in Table 3. Figure 5 shows a typical wind speed time series generated at a sampling rate of $10 \mathrm{~Hz}$ over a 10 minute duration.

3.2.2. Damage Cases. Different damage cases are considered in the simulation, consisting of different locations and severities. The four damage locations under study are schematized in Figure 6, represented by the red-dashed parallelograms. The blue circles in the figure represent the location of the simulated 74 sensors. Damage location 1 (Figure 6(a)) is a vertical defect close to the root, damage location 2 (Figure 6(b)) is a horizontal defect close to the root, damage location 3 (Figure 6(c)) is a vertical defect close to midlength, and damage location 4 (Figure $6(\mathrm{~d})$ ) is the combination of damage locations 1 and 3.

Damage is introduced as a change in the stiffness of the laminate layer 2. Different damage severities are considered
TABLE 3: Wind speed model parameters.

\begin{tabular}{lc}
\hline Parameter & Value \\
\hline$v_{a}$ & $20 \mathrm{~m} / \mathrm{s}$ \\
$A_{\text {ramp }}$ & $3 \mathrm{~m} / \mathrm{s}$ \\
$A_{\text {gust }}$ & $-2 \mathrm{~m} / \mathrm{s}$ \\
$T_{s r}$ & $50 \mathrm{~s}$ \\
$T_{e r}$ & $150 \mathrm{~s}$ \\
$T_{s g}$ & $100 \mathrm{~s}$ \\
$T_{e g}$ & $250 \mathrm{~s}$ \\
$h$ & $40 \mathrm{~m}$ \\
$l$ & $600 \mathrm{~m}$ \\
$z_{0}$ & $0.2 \mathrm{~m}$ \\
$N_{\omega}$ & 23 \\
$\omega_{c}$ & $20 \pi \mathrm{rad} / \mathrm{s}$ \\
\hline
\end{tabular}

under load location 1 (Figure 6(a)), which correspond to different changes in the first natural frequencies of the blade: $1 \%$, $2 \%, 5 \%, 10 \%$, and $15 \%(35.5 \%, 54.8 \%, 80.6 \%, 92.3 \%$, and $96.7 \%$ stiffness loss of the damaged elements in the strong axis). All SECs are simulated as errorless and noiseless sensors.

\section{Simulation Results}

Simulations were conducted on the numerical model to study the capacity of the novel sensor network at detecting, localizing, and estimating the severity of damage. The first set of simulations is conducted on a single damage location (location 1) of different severity, equivalent to $1 \%, 2 \%, 5 \%, 10 \%$, and $15 \%$ changes in the first natural frequency through a change in the layer's stiffness. Figures 7(a)-7(e) are damage maps $J$ (Equation (9)) constructed by computing the relative signal with four closest neighbors and using the undamaged case as the reference relative response map $\bar{R}_{t^{*}}$. All damage plots were performed by creating triangular elements between sensors and linearly interpolating results between points to create a smoother variation in colors. The damaged area is clearly identified by the darker red region (positive values) for all damage levels. However, the maximum $J$ value within this region is relatively low for the $1 \%$ damage case, which may be harder to identify in cases of high noise or sensor malfunction. The dark blue area (negative values) under the damaged area indicates that the load path migrated through that region and formed a plastic deformation, because the relative response of the sensors within that region increased. Figure 7(f) summarizes the maximum and minimum values for $J$ taken for the sensors located within the region $1 \leq x \leq$ $2 \mathrm{~m}$. There is a sequential trend of the maximum value of $J$, which is located within the damage area, with the increasing damage level. An inspection of the minimum value of $J$, located under the damage, also exhibits a similar trend. This demonstrates that the sensing method can further be utilized to evaluate the severity of the damage.

It is also interesting to assess the benefits of the additive strain measurements feature of the SEC by comparing its performance against unidirectional sensors (e.g., resistive foil gauges). Figure 8 is used to compare the damage maps $J$ for 


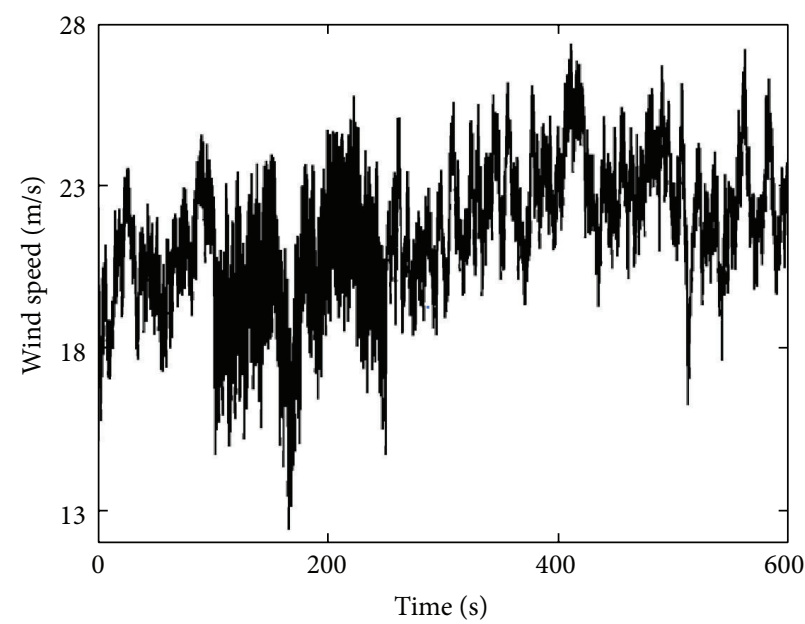

(a)

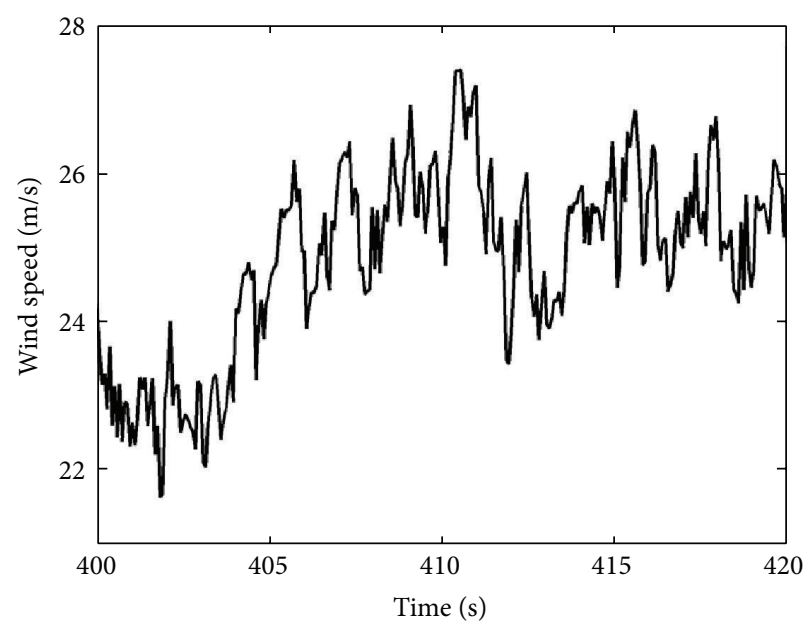

(b)

FIgURE 5: Typical realization of a wind time series at a $10 \mathrm{~Hz}$ sampling rate: (a) 10-minute duration and (b) zoom on 20 seconds.

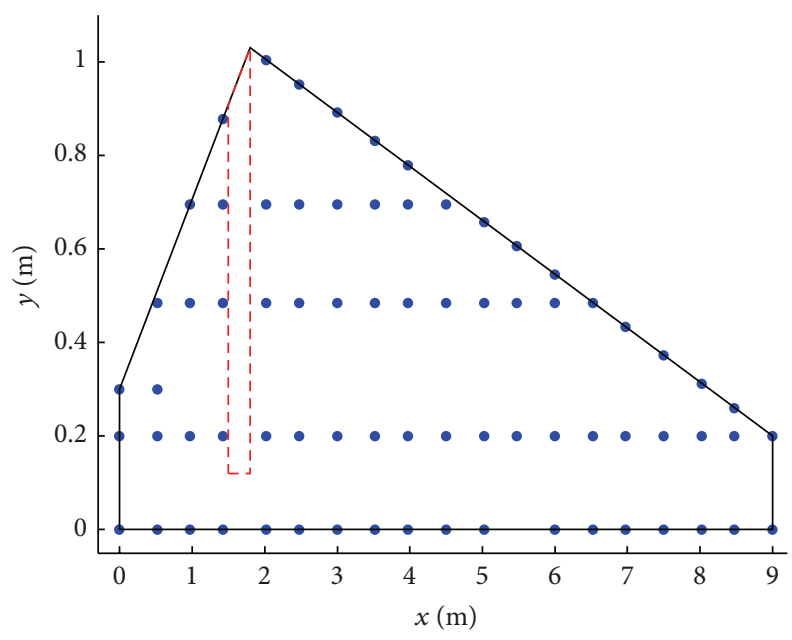

(a)

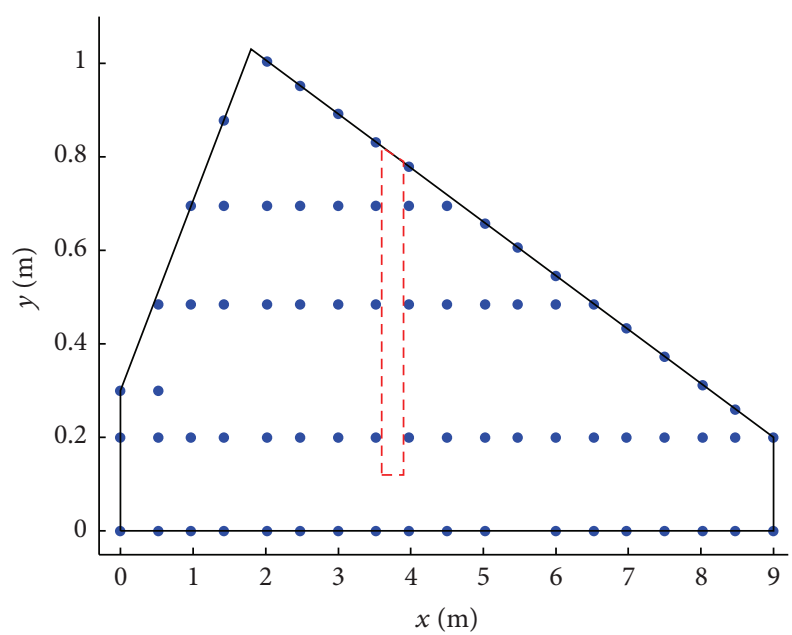

(c)

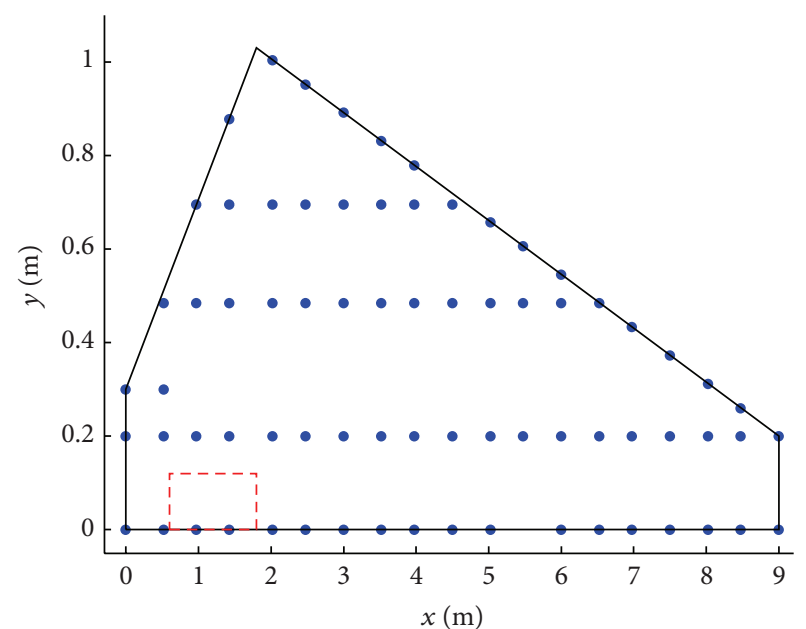

(b)

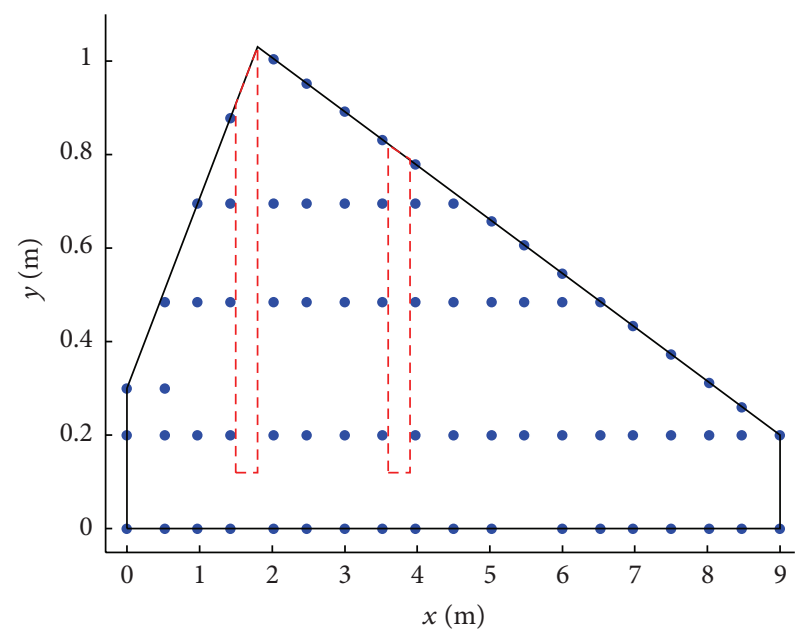

(d)

Figure 6: Damage locations under study: (a) location 1, (b) location 2, (c) location 3, and (d) location 4. 


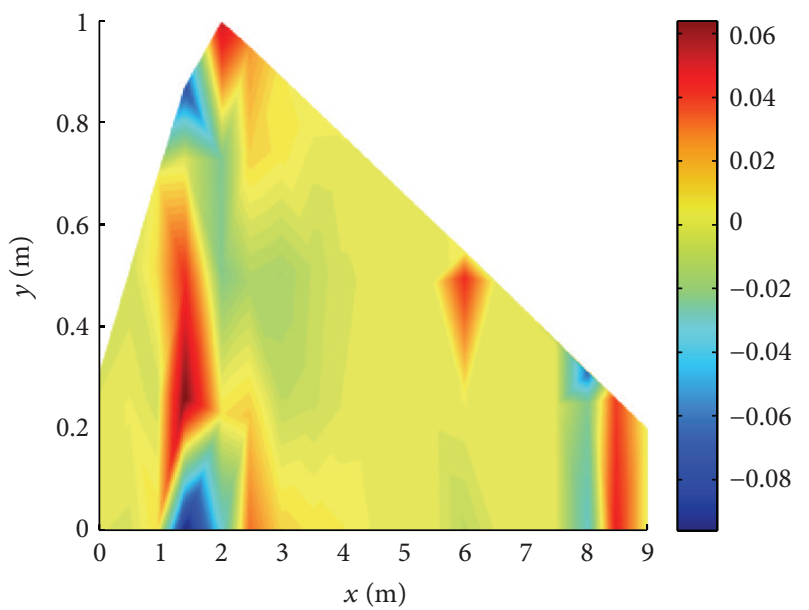

(a)

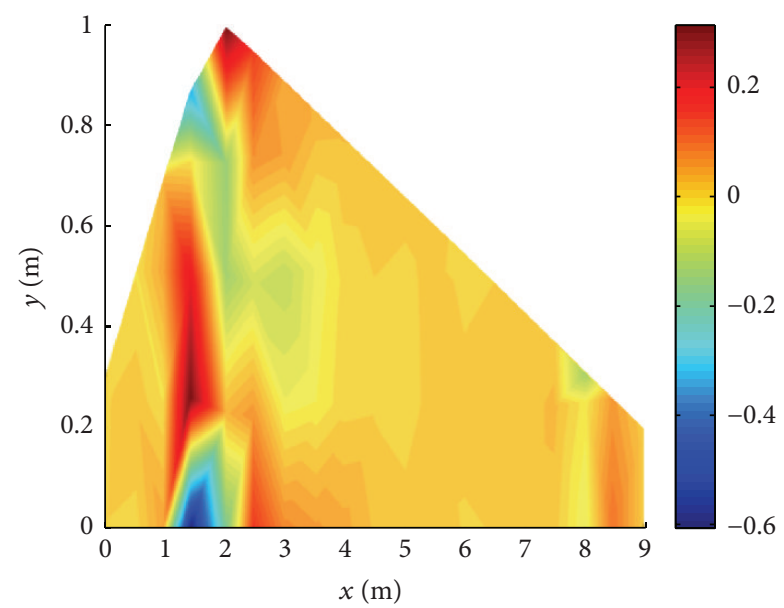

(c)

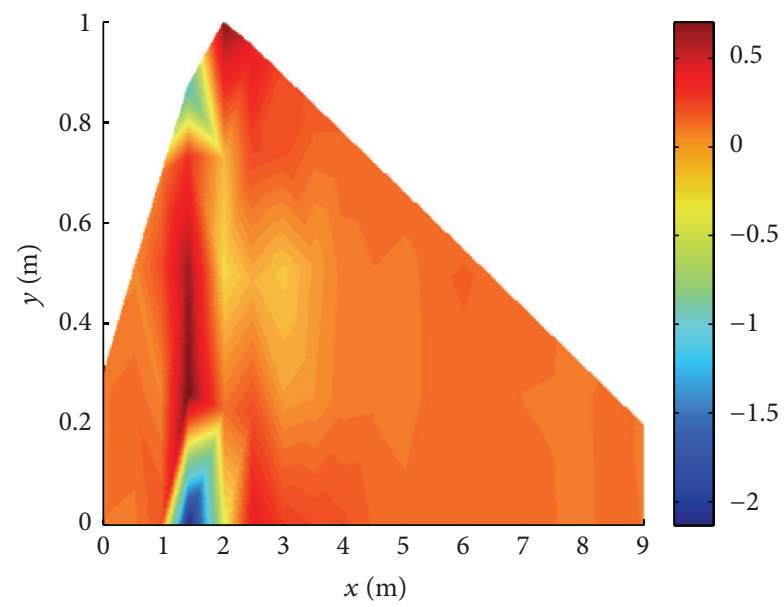

(e)

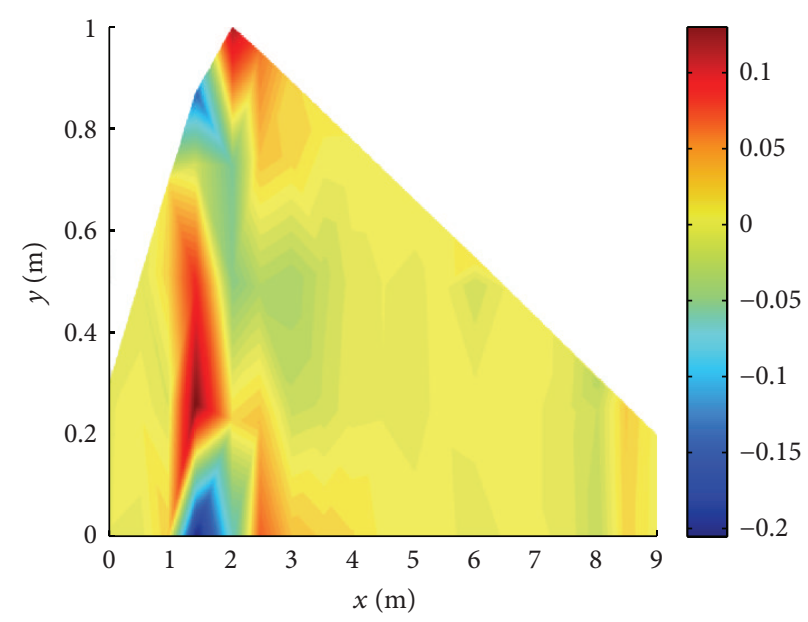

(b)

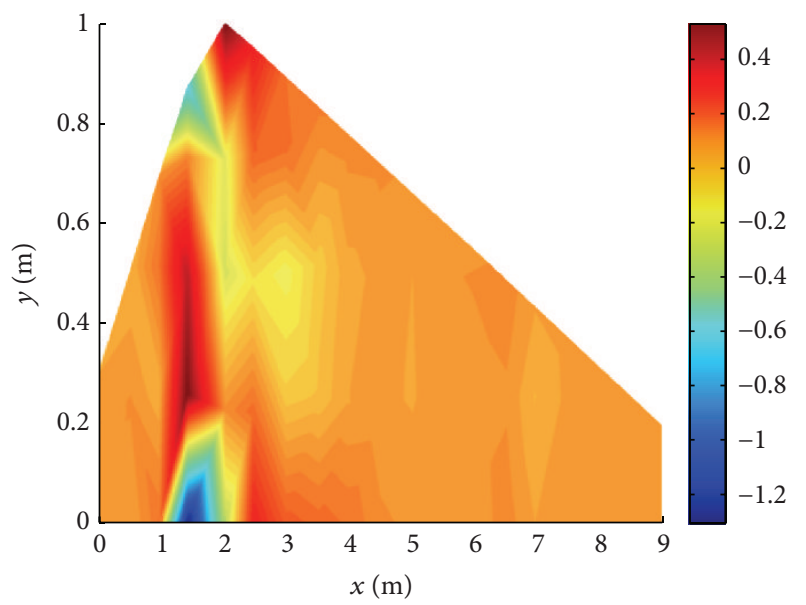

(d)

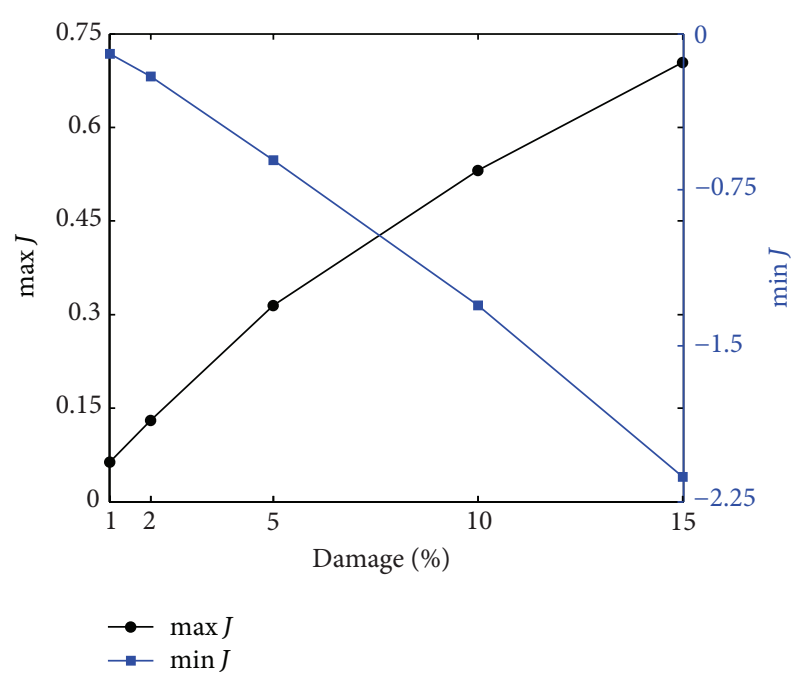

(f)

Figure 7: Damage maps $J$ for damage cases corresponding to (a) $1 \%$, (b) $2 \%$, (c) $5 \%$, (d) $10 \%$, and (e) $15 \%$ reduction in the first natural frequency of the blade. 


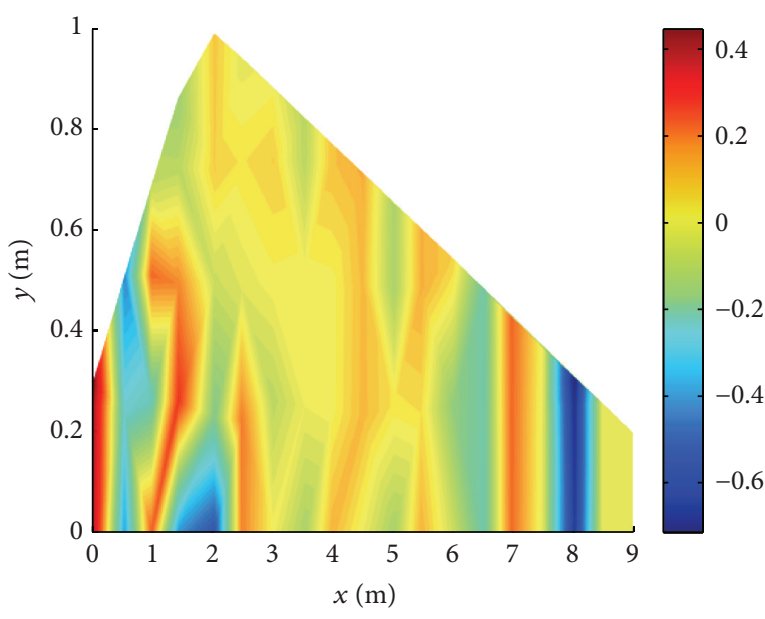

(a)

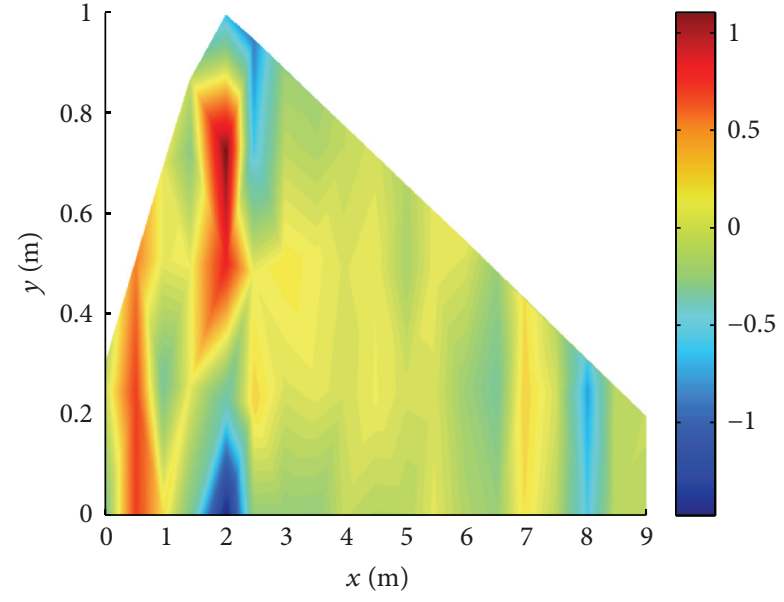

(b)

FIgURE 8: Comparison of damage maps $J$ for $5 \%$ damage using (a) strain along the $x$-axis only and (b) strain along the $y$-axis only.

the $5 \%$ damage case at location 1 obtained using the additive strain $\varepsilon_{x}+\varepsilon_{y}$ from the SEC network (Figure $7(\mathrm{c})$ ) with the damage maps obtained using unidirectional strain along the $x$-axis $\varepsilon_{x}$ (Figure 8(a)) and along the $y$-axis $\varepsilon_{y}$ (Figure 8(b)). The unidirectional strain data along $x$ (Figure $8(\mathrm{a})$ ) is not capable of clearly identifying damage, showing different possible regions of highly positive and negative $J$ values, while the unidirectional strain data along $y$ (Figure 8(b)) does provide a good detection and identification of the damage, with a substantially higher $J$ value, but also it exhibits a region of possible damage close to the root. Note that these results were obtained assuming errorless and noiseless sensors. However, the precision of off-the-shelf resistive foil gauges is beyond the precision of the SEC, as indicated in Section 2.3. Research is being conducted to improve the performance of the SEC, notably via the development of dedicated electronics.

Figures 9(a)-9(c) show the damage maps $J$ obtained from the SEC network for different damage locations. All simulated damage cases correspond to an approximate loss of $5 \%$ in the blade's first natural frequency. The sensing strategy is successful at localizing all damage. There is a loss in resolution for the joint damage case (location 4). This can be explained by the lower number of sensors located between both damage lines.

\section{Sparser Sensor Network via Kriging}

This section investigates the possibility of condition assessment from a sparser sensor network that would result from missing sensors or hardware malfunctions, for instance. Additional simulations are conducted by removing 31 sensors, which correspond to $42 \%$ of the sensors used in the previous section. Figure 10 shows the distribution of the new sensor network, where the removed sensors are denoted "inactive." The damage detection, localization, and prognosis exercise is repeated on the different damage levels for damage location 1 using the same wind realization. This time, the map $J$ is constructed by computing the relative response from the two closest neighbors only, due to the sparsity of the network yielding inaccurate damage localization results using a higher number of neighbors. Figure 10 shows a similar trend as in Figure 7, but with a notable loss in resolution.

In order to recover the resolution of the figure, albeit in absence of dense sensory feedback, Kriging is implemented. In the example explored herein, the spatial coordinates of the sensor locations comprise the inputs $x$, while the additive strain measurements comprise the outputs $s(x)$ in the observed (red squares) and unobserved (blue circles) locations in Figure 10. Kriging provides a prediction of the output variable in the unobserved locations as

$$
s(x)=\alpha^{T} \phi(\theta, x)+\beta^{T} f(x),
$$

where $f(x)$ denotes a regression (polynomial) part, $\phi(\theta, x)$ denotes a correlation (radial) part, and $\alpha$ and $\beta$ are coefficient vectors. For further implementation details, the interested reader is referred to [31]. The DACE A MATLAB Kriging Toolbox [32] is herein used for the analysis, where first order polynomials are used for the regression part and cubic spline functions are used for the correlation part. In order to appropriately select these functions, the algorithm is trained via use of the data extracted in the undamaged state, where it assumed that information from the dense (reference) sensor network is available. Once the configuration parameters are selected, Kriging is employed for inferring the additive strain time histories in the locations of the "virtual sensors" and the process outlined earlier for detecting damage is once again enforced.

The results are plotted in Figure 12 for various damage levels. By comparing with Figure 11 (sparse network) and Figure 7 (original network), it can be observed that the resolution has been recovered. This example demonstrates that the coupling of the proposed sensing solution with advanced postprocessing schemes results in a resilient framework for strain monitoring of wind turbine blades.

\section{Conclusion}

A strategy for damage detection, localization, and prognosis over large structural surfaces has been proposed. It consists of 


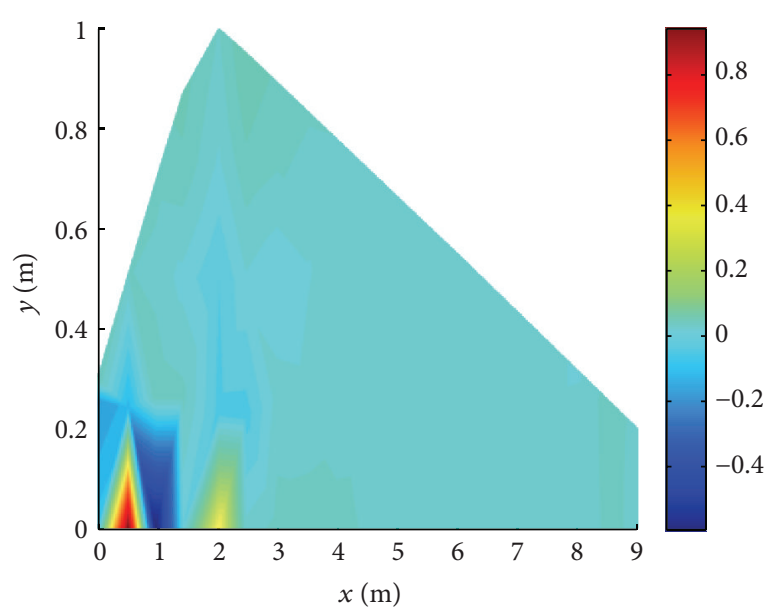

(a)

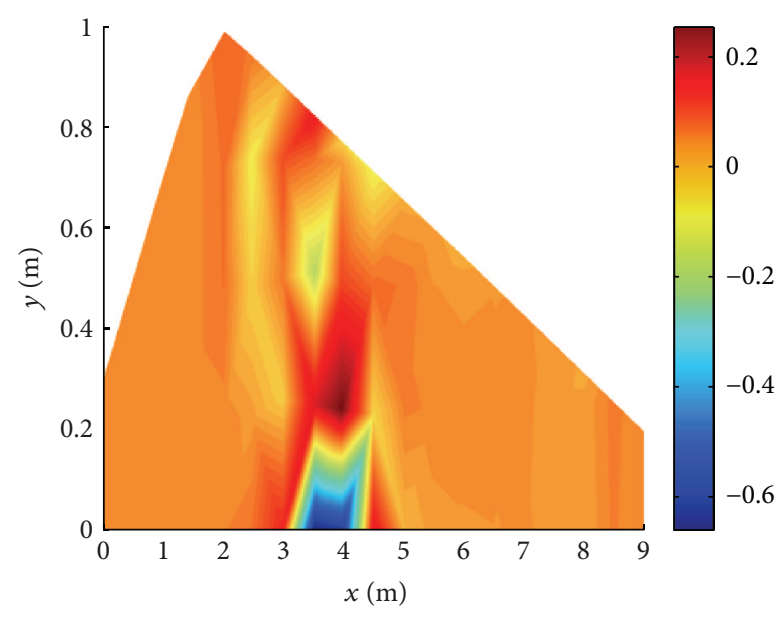

(b)

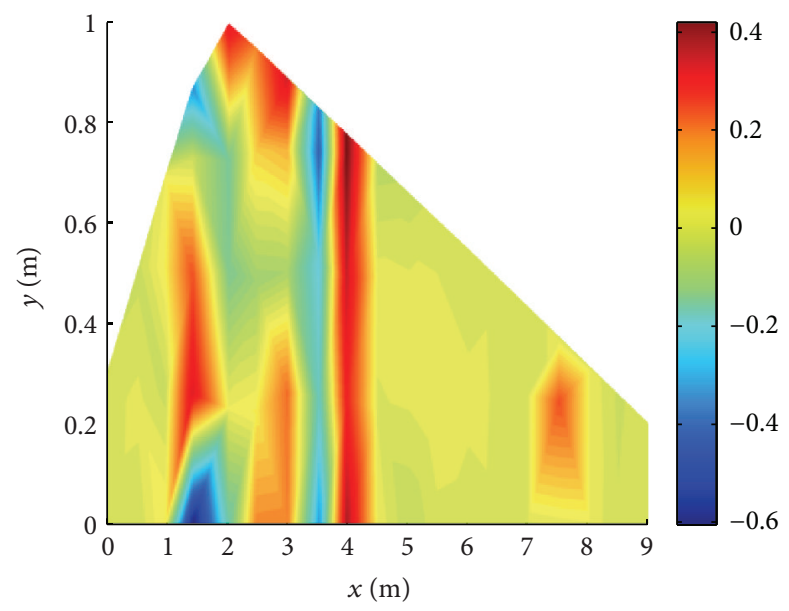

(c)

Figure 9: Damage maps $J$ for different damage locations: (a) location 2, (b) location 3, and (c) location 4.

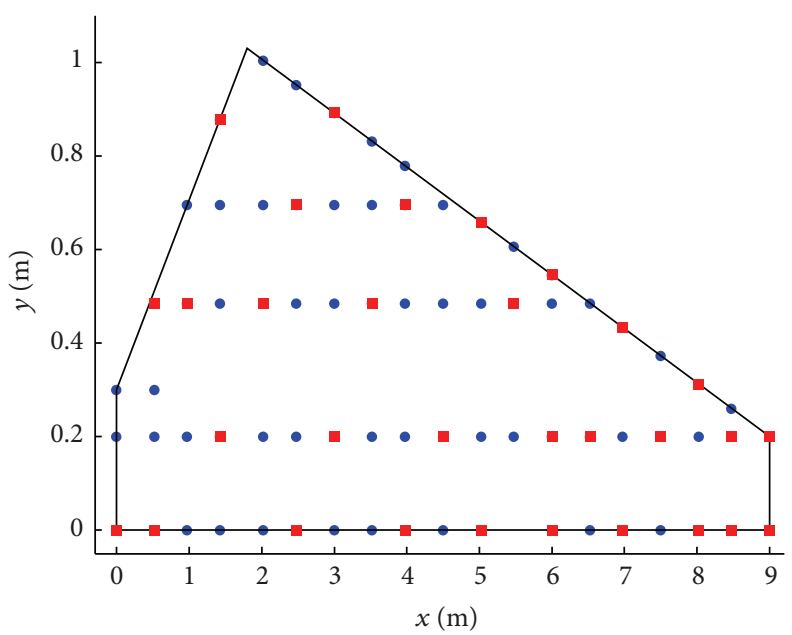

- Active sensor

- Inactive sensor

FIGURE 10: Sparse sensor network under investigation. 


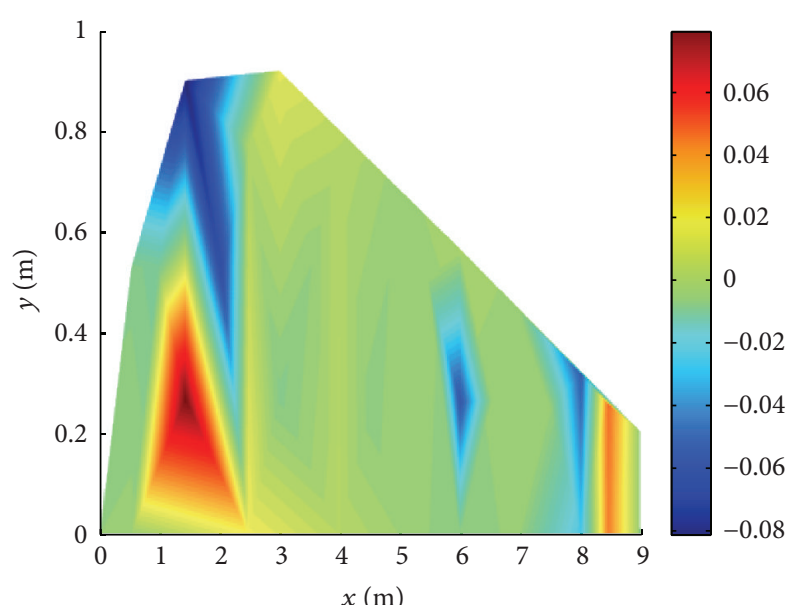

(a)

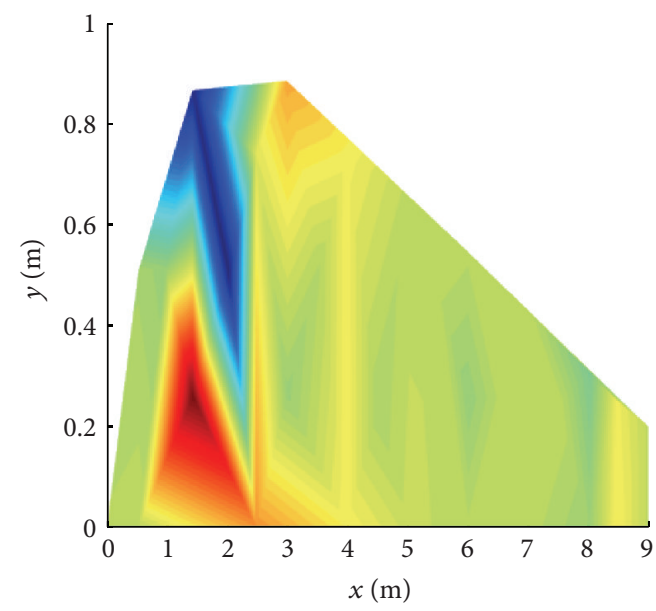

(c)

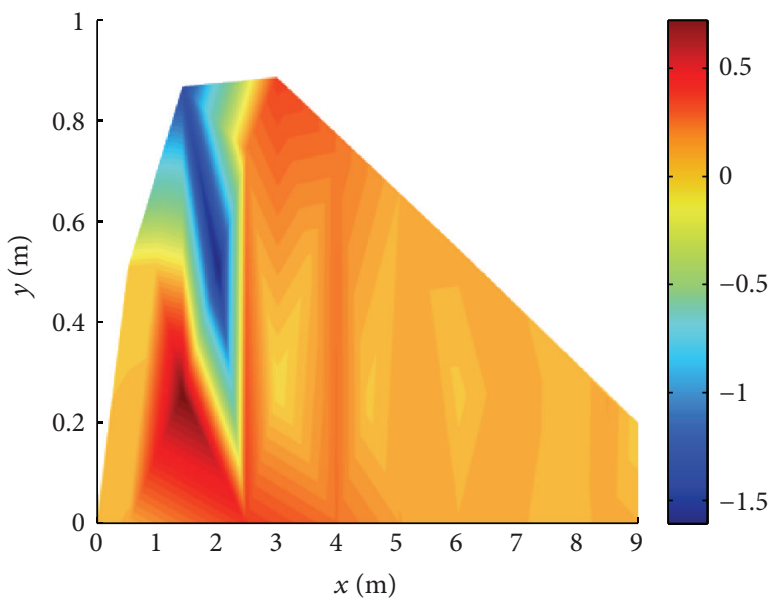

(e)

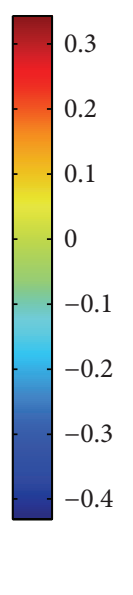

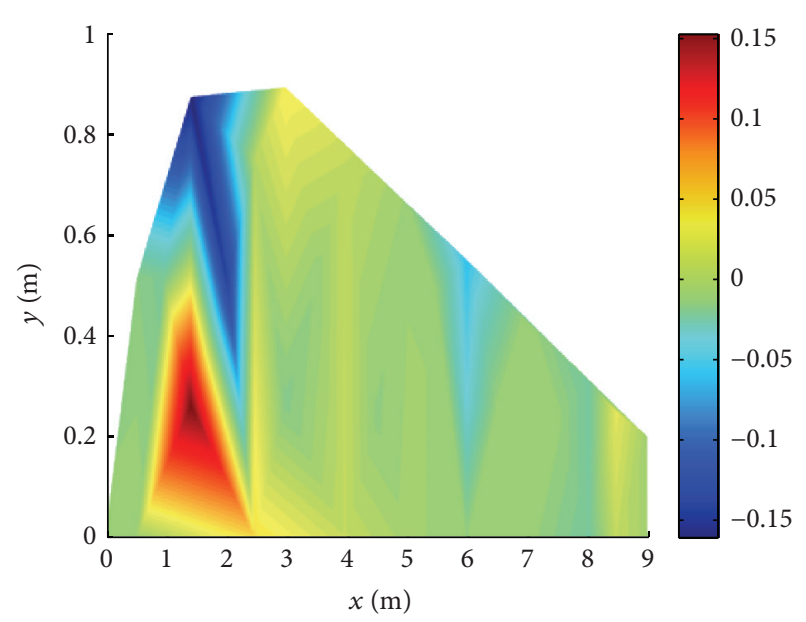

(b)

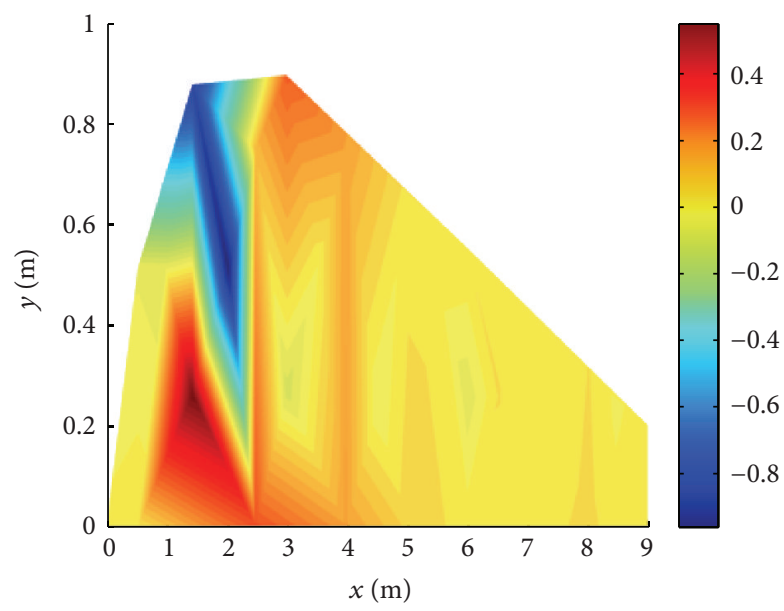

(d)

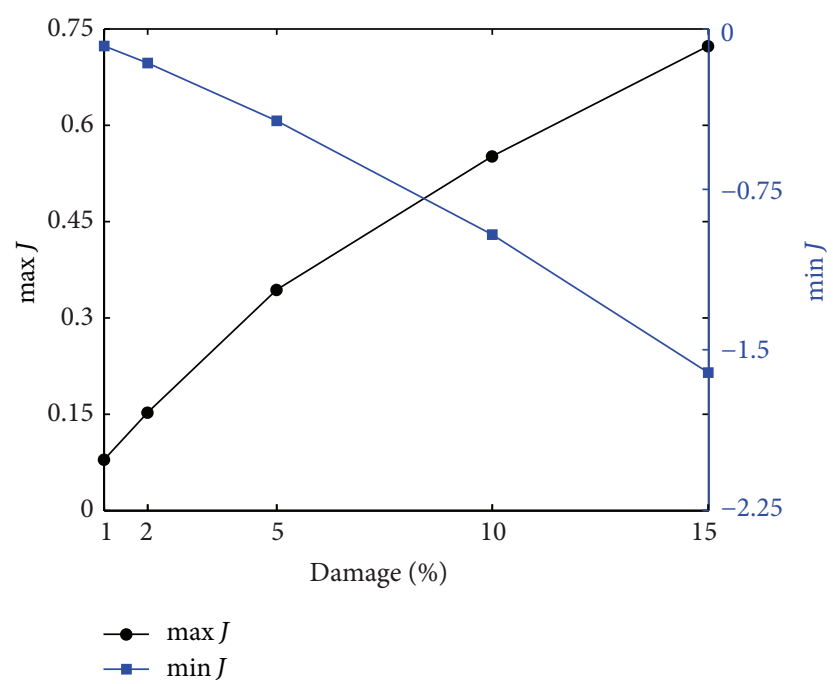

(f)

FIGURE 11: Damage maps $J$ for damage cases when considering the sparse sensor network of Figure 10. Damage corresponds to (a) $1 \%$, (b) $2 \%$, (c) $5 \%$, (d) $10 \%$, and (e) $15 \%$ reduction in the first natural frequency of the blade. 


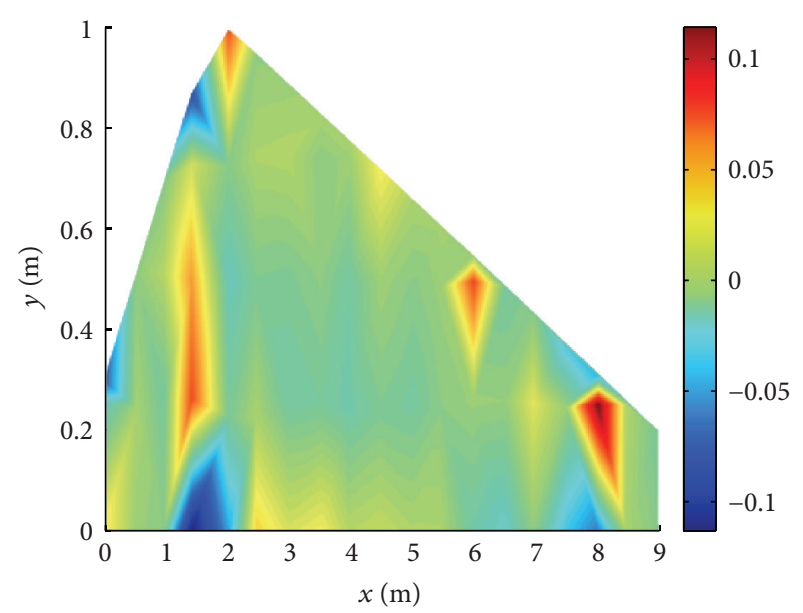

(a)

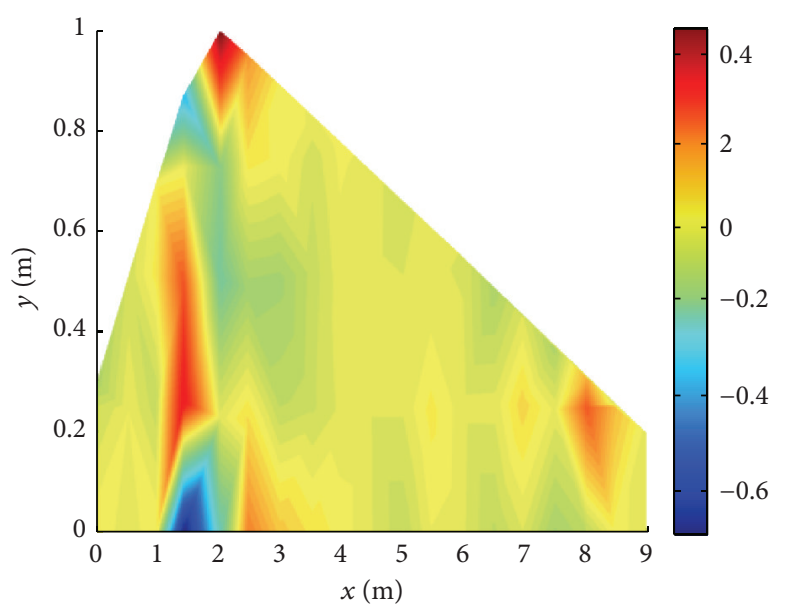

(c)

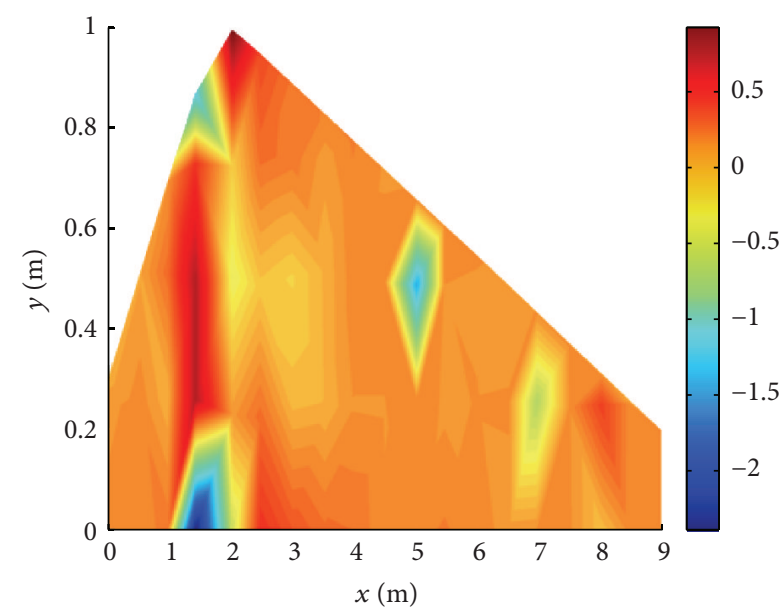

(e)

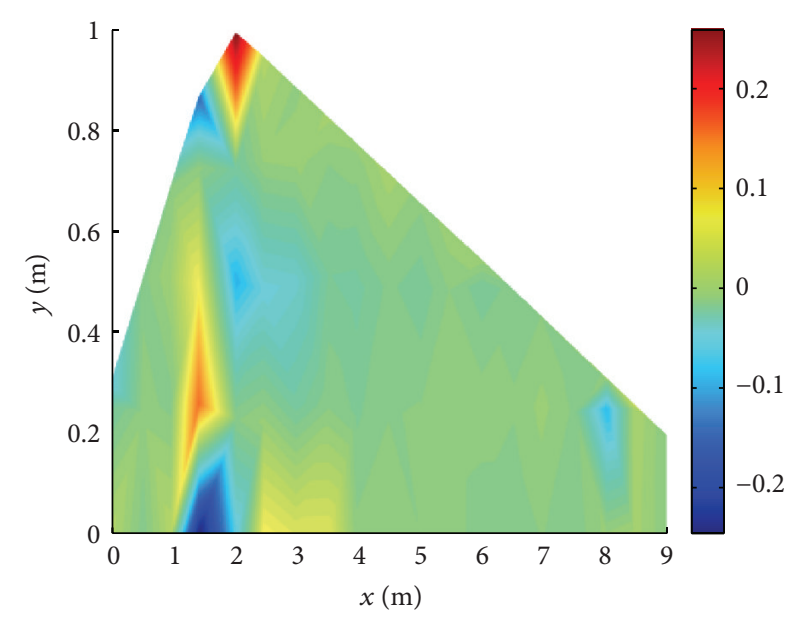

(b)

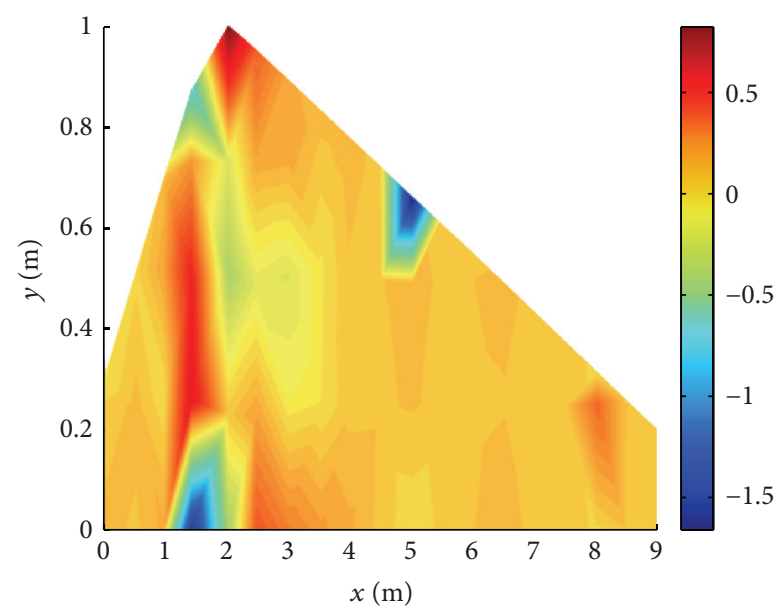

(d)

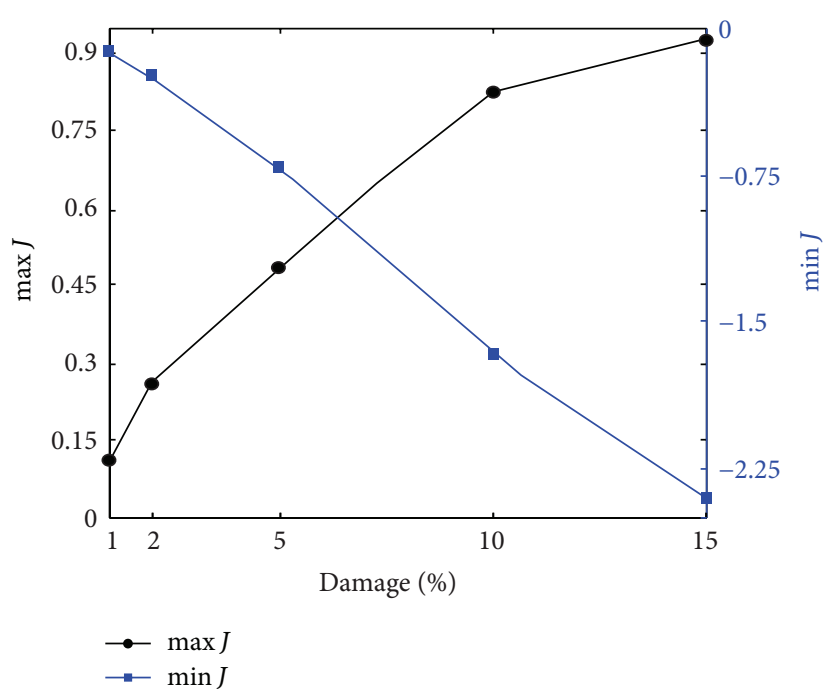

(f)

Figure 12: Damage maps $J$ for damage cases when considering the sparse sensor network of Figure 10 and Kriging interpolation. Damage corresponds to (a) $1 \%$, (b) $2 \%$, (c) $5 \%$, (d) $10 \%$, and (e) $15 \%$ reduction in the first natural frequency of the blade. 
the deployment of a novel sensor, the soft elastomeric capacitor (SEC), in a network configuration, combined with a simple data-driven algorithm based on raw strain data. Numerical simulations considering a wind turbine blade as the benchmark case study have clearly demonstrated the effectiveness of the proposed structural health monitoring solution in detecting a damage, providing its location, and ranking its severity. Results have also highlighted that the use of the SEC may provide enhanced damage detection capabilities in comparison with conventional directional strain gauges, because of its additive strain measurement feature. Finally, the application of the concepts of Kriging has strengthened the sensor network approach by replacing missing or malfunctioning sensors by virtual sensors, yet providing a high level of damage detection resolution. The overall performance of the SEC at the condition assessment task, combined with its high scalability, makes the technology a promising candidate for structural health monitoring of large and complex geometries.

\section{Conflict of Interests}

The authors declare that there is no conflict of interests regarding the publication of this paper.

\section{Acknowledgments}

This work is supported from the Iowa Alliance for Wind Innovation and Novel Development (IAWIND) (Grant 1001062565) and the Iowa Energy Center (Grant 13-02). Their support is gratefully acknowledged.

\section{References}

[1] A. Alvandi and C. Cremona, "Assessment of vibration-based damage identification techniques," Journal of Sound and Vibration, vol. 292, no. 1-2, pp. 179-202, 2006.

[2] F. Magalhães, A. Cunha, and E. Caetano, "Vibration based structural health monitoring of an arch bridge: from automated OMA to damage detection," Mechanical Systems and Signal Processing, vol. 28, pp. 212-228, 2012.

[3] E. J. Cross, G. Manson, K. Worden, and S. G. Pierce, "Features for damage detection with insensitivity to environmental and operational variations," Proceedings of the Royal Society A, vol. 468, no. 2148, pp. 4098-4122, 2012.

[4] S. Kharroub, S. Laflamme, S. Madbouly, and F. Ubertini, "Biobased soft elastomeric capacitor for structural health monitoring applications," Structural Health Monitoring, vol. 14, no. 2, pp. 158-167, 2014.

[5] L. Yu, V. Giurgiutiu, P. Ziehl, D. Ozevin, and P. Pollock, "Steel bridge fatigue crack detection with piezoelectric wafer active sensors," in Sensors and Smart Structures Technologies for Civil, Mechanical, and Aerospace Systems, Proceedings of the SPIE, 76471Y, March 2010.

[6] M. Gresil, L. Yu, Y. Shen, and V. Giurgiutiu, "Predictive model of fatigue crack detection in thick bridge steel structures with piezoelectric wafer active sensors," Smart Structures and Systems, vol. 12, no. 2, pp. 97-119, 2013.

[7] D. C. Lee, J. J. Lee, I. B. Kwon, and D. C. Seo, "Monitoring of fatigue damage of composite structures by using embedded intensity-based optical fiber sensors," Smart Materials and Structures, vol. 10, no. 2, pp. 285-292, 2001.

[8] H. Tsuda, J.-R. Lee, Y. Guan, and J. Takatsubo, "Investigation of fatigue crack in stainless steel using a mobile fiber Bragg grating ultrasonic sensor," Optical Fiber Technology, vol. 13, no. 3, pp. 209-214, 2007.

[9] B. Glisic and Y. Yao, "Fiber optic method for health assessment of pipelines subjected to earthquake-induced ground movement," Structural Health Monitoring, vol. 11, no. 6, pp. 696-711, 2012.

[10] L. Gao, E. T. Thostenson, Z. Zhang, J.-H. Byun, and T.-W. Chou, "Damage monitoring in fiber-reinforced composites under fatigue loading using carbon nanotube networks," Philosophical Magazine, vol. 90, no. 31-32, pp. 4085-4099, 2010.

[11] A. D’Alessandro, F. Ubertini, A. L. Materazzi, S. Laflamme, and M. Porfiri, "Electromechanical modelling of a new class of nanocomposite cement-based sensors for structural health monitoring," Structural Health Monitoring, vol. 14, no. 2, pp. 137-147, 2015.

[12] F. Ubertini, A. L. Materazzi, A. D’Alessandro, and S. Laflamme, "Natural frequencies identification of a reinforced concrete beam using carbon nanotube cement-based sensors," Engineering Structures, vol. 60, pp. 265-275, 2014.

[13] I. Kang, M. J. Schulz, J. H. Kim, V. Shanov, and D. Shi, "A carbon nanotube strain sensor for structural health monitoring," Smart Materials and Structures, vol. 15, no. 3, article 737, 2006.

[14] K. J. Loh, T.-C. Hou, J. P. Lynch, and N. A. Kotov, "Carbon nanotube sensing skins for spatial strain and impact damage identification," Journal of Nondestructive Evaluation, vol. 28, no. 1, pp. 9-25, 2009.

[15] R. K. Srivastava, V. S. M. Vemuru, Y. Zeng et al., "The strain sensing and thermal-mechanical behavior of flexible multiwalled carbon nanotube/polystyrene composite films," Carbon, vol. 49, no. 12, pp. 3928-3936, 2011.

[16] Y. Hu, W. S. A. Rieutort-Louis, J. Sanz-Robinson et al., "Largescale sensing system combining large-area electronics and cmos ics for structural-health monitoring," IEEE Journal of Solid-State Circuits, vol. 49, no. 2, pp. 513-523, 2014.

[17] S.-T. Tung, Y. Yao, and B. Glisic, "Sensing sheet: the sensitivity of thin-film full-bridge strain sensors for crack detection and characterization," Measurement Science and Technology, vol. 25, no. 7, Article ID 075602, 2014.

[18] S. Laflamme, H. S. Saleem, B. K. Vasan et al., "Soft elastomeric capacitor network for strain sensing over large surfaces," IEEE/ASME Transactions on Mechatronics, vol. 18, no. 6, pp. 1647-1654, 2013.

[19] S. Kharroub, S. Laflamme, C. Song, D. Qiao, B. Phares, and J. $\mathrm{Li}$, "Smart sensing skin for detection and localization of fatigue cracks," Smart Materials and Structures, vol. 24, no. 6, Article ID 065004, 2015.

[20] J. Wu, C. Song, H. S. Saleem, A. Downey, and S. Laflamme, "Network of flexible capacitive strain gauges for the reconstruction of surface strain," Measurement Science and Technology, vol. 26, no. 5, Article ID 055103, 2015.

[21] D. S. Berry and D. E. Berg, "Blade system design studies phase II: final project report," Sandia Report SAND2008-4648, 2008.

[22] S. Laflamme, M. Kollosche, J. J. Connor, and G. Kofod, "Robust flexible capacitive surface sensor for structural health monitoring applications," Journal of Engineering Mechanics, vol. 139, no. 7, pp. 879-885, 2013. 
[23] D. Berry and T. Ashwill, Design of 9-Meter Carbon-Fiberglass Prototype Blades: Cx-100 and tx-100. SAND2007-0201, Sandia National Laboratories, Albuquerque, NM, USA, 2007.

[24] J. R. White, D. E. Adams, and M. A. Rumsey, "Modal analysis of CX-100 rotor blade and micon 65/13 wind turbine," in Structural Dynamics and Renewable Energy, Volume 1, Conference Proceedings of the Society for Experimental Mechanics Series, pp. 15-27, Springer, New York, NY, USA, 2011.

[25] N. Dervilis, M. Choi, S. G. Taylor et al., "On damage diagnosis for a wind turbine blade using pattern recognition," Journal of Sound and Vibration, vol. 333, no. 6, pp. 1833-1850, 2014.

[26] J. G. Slootweg, S. W. H. De Haan, H. Polinder, and W. L. Kling, "General model for representing variable speed wind turbines in power system dynamics simulations," IEEE Transactions on Power Systems, vol. 18, no. 1, pp. 144-151, 2003.

[27] M. Shinozuka and C.-M. Jan, "Digital simulation of random processes and its applications," Journal of Sound and Vibration, vol. 25, no. 1, pp. 111-128, 1972.

[28] F. Ubertini and F. Giuliano, "Computer simulation of stochastic wind velocity fields for structural response analysis: comparisons and applications," Advances in Civil Engineering, vol. 2010, Article ID 749578, 20 pages, 2010.

[29] P. Mendis, T. Ngo, N. Haritos, A. Hira, B. Samali, and J. Cheung, "Wind loading on tall buildings," Electronic Journal of Structural Engineering, vol. 7, pp. 41-54, 2007.

[30] J. N. Yang, A. K. Agrawal, B. Samali, and J.-C. Wu, "Benchmark problem for response control of wind-excited tall buildings," Journal of Engineering Mechanics, vol. 130, no. 4, pp. 437-446, 2004.

[31] H. B. Nielsen, S. N. Loophaven, and J. Søndergaard, Surrogate modelling by kriging [Lecture Notes, Informatics and Mathematical Modelling, M.S. thesis], Technical University of Denmark, Lyngby, Denmark, 2003.

[32] H. B. Nielsen, S. N. Loophaven, and J. Søndergaard, DACE: A Natlab Kriging Toolbox. Version 2.0, 2002. 


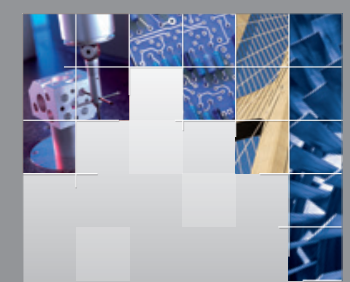

\section{Enfincering}
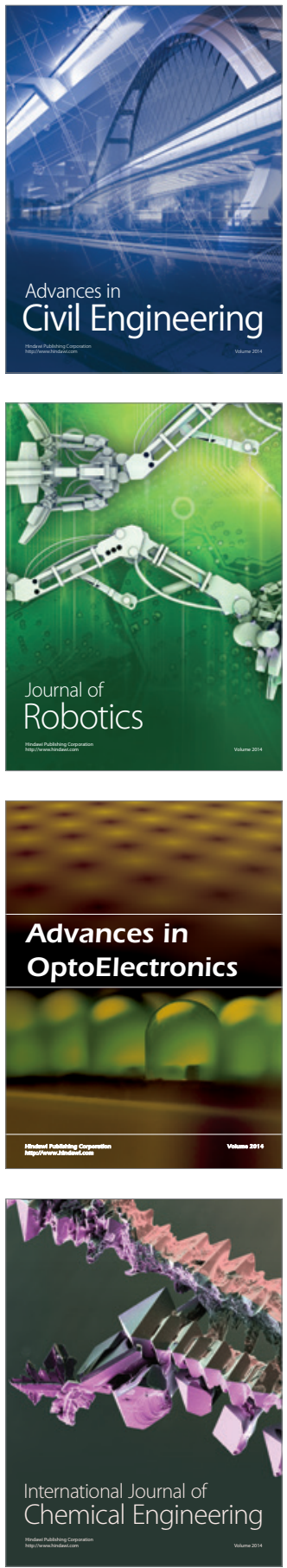

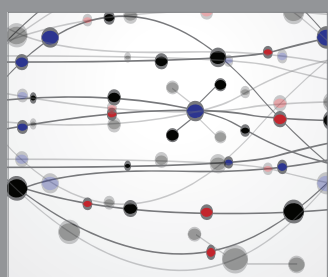

The Scientific World Journal

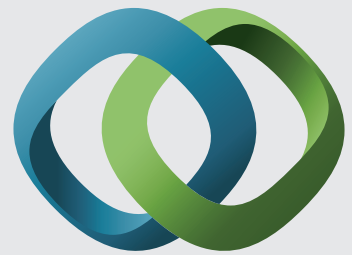

\section{Hindawi}

Submit your manuscripts at

http://www.hindawi.com
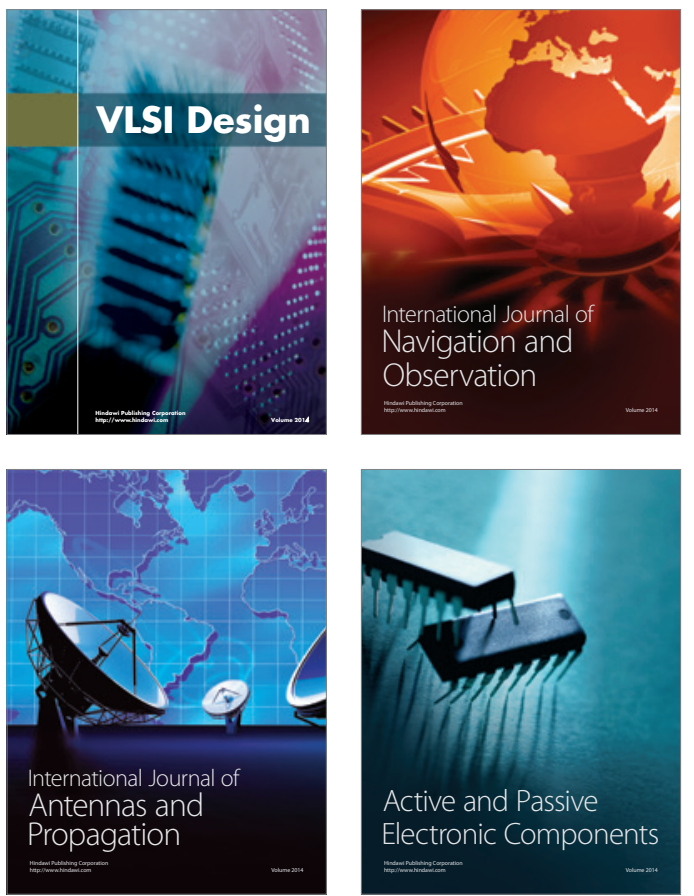
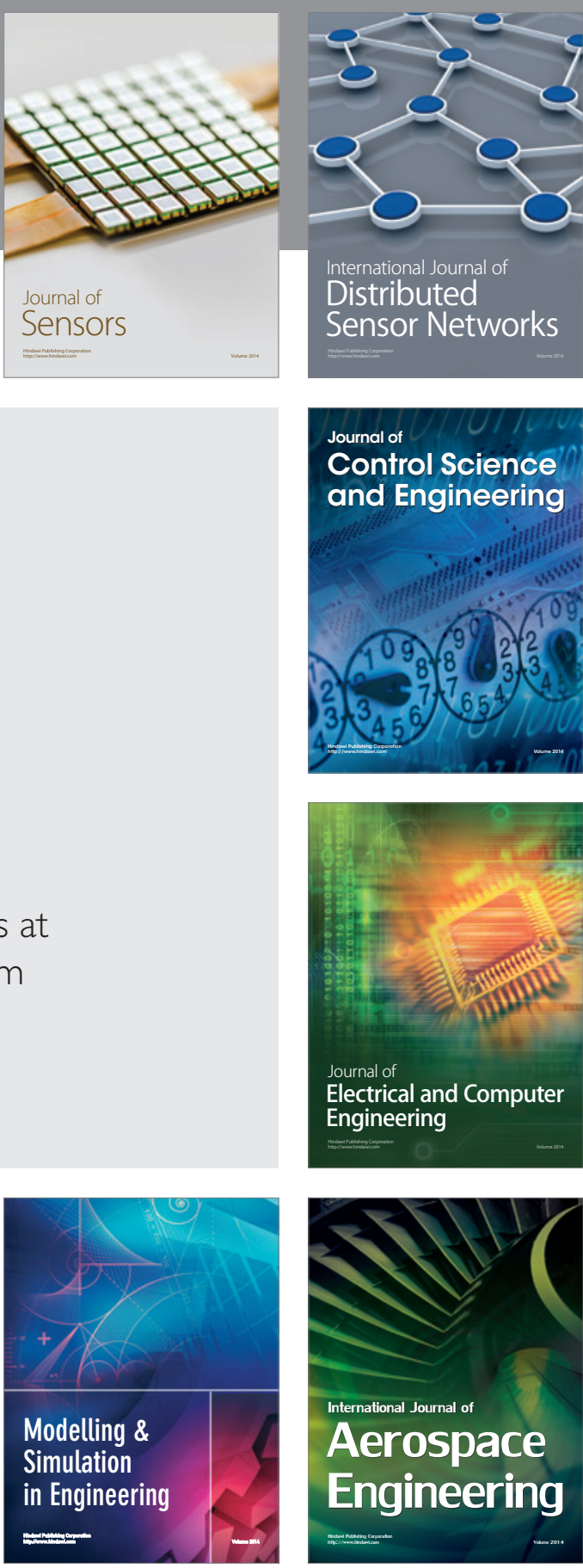

International Journal of

Distributed

Sensor Networks

Journal of

Control Science

and Engineering
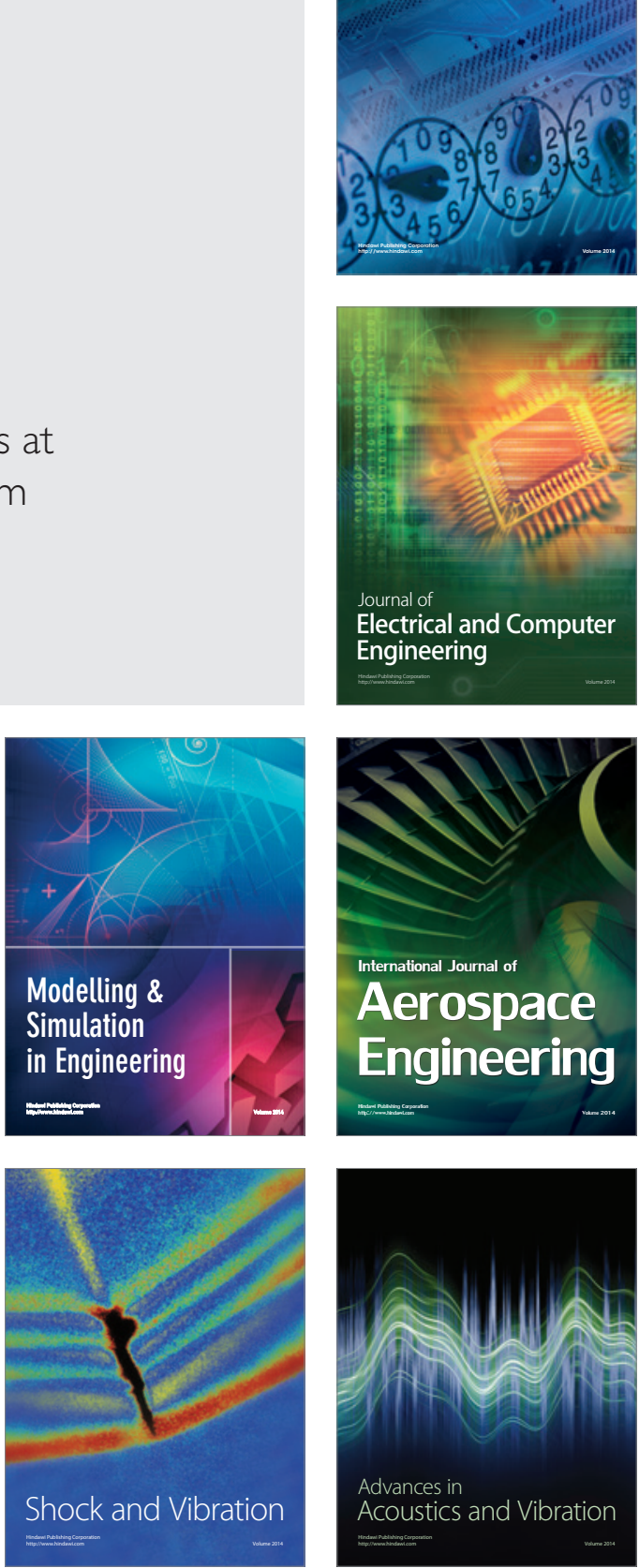